Check for updates

The BMJ

Cite this as: BMJ 2020;369:m2325 http://dx.doi.org/10.1136/bmj.m2325 Published: 10 June 2020

\section{Covid-19: Clinicians must be able to access all test results, pathologists}

\section{say}

Gareth lacobucci

Future testing programmes for covid-19 or other diseases must be designed so that all results can be swiftly accessed by clinicians in primary and secondary care, the Royal College of Pathologists has urged.

In its national blueprint for testing, the college warned that problems such as slow turnaround of results and lack of clinical oversight must be "urgently addressed" in future testing programmes, as the UK moves beyond the peak of the pandemic. ${ }^{1}$

The document outlines seven key principles for the UK to adhere to when constructing future testing policy, beginning with the fundamental notion that tests must be "the right one, at the right time, and with the correct result." Any testing programme must be clear on what its purpose is, whether it be diagnosis, screening, or gathering data to understand the spread, or prevalence, of disease in a population, it adds.

The strategy says that test results should include appropriate clinical interpretation and that tests not designed and validated for home use should be carried out by skilled trained laboratory professionals to "recognised and accredited" standards. Standards and quality assurance should be upheld regardless of where and how tests are being carried out, it adds.

The strategy also emphasises that problems with testing-particularly for infectious diseases-can affect disease spread, risk assessment, morbidity, mortality, and population health. Examples of problems that can occur include poor specimen taking, poor labelling or poor transcription of details, slow turnaround of results, poor quality control, ineffective communication of the result, inappropriate application of the result, and lack of clinical input or oversight. "Many of these issues have been seen in recent times, all of which must be urgently addressed," the college warns.

The strategy also emphasises the importance of data connectivity and calls for consistent coding of tests to be rolled out "at speed" to enable primary and secondary care and public health bodies to access results.

Another principle is to ensure that people being tested are informed about why they are being tested, the implications and limitations of their results, that they have access to their results and are informed if their data becomes part of a research programme and of their rights to be excluded if they so wish.

At societal level, the college says, information about testing "needs to be in plain language and accessible to all in a range of formats."
Jo Martin, president of the Royal College of Pathologists, said: "This document sets out a vision for a future strategy with which clinical, scientific, and policy stakeholders, including patient advocacy groups, can align.

"Testing is not something that is just done and counted. It is a process with clinical purposes for individual patients, for those who care for them, and for the population at large. It is a conscious and targeted use of valuable materials and highly skilled professionals within the context of a pathway and purpose."”

The college said that the strategy would be iterative and would evolve as evidence emerged. Royal College of Pathologists. Covid-19 testing: a national strategy. 2020.
https://www.rcpath.org/profession/on-the-agenda/covid-19-testing-a-na-
tional-strategy.html

This article is made freely available for use in accordance with BMJ's website terms and conditions for the duration of the covid-19 pandemic or until otherwise determined by BMJ. You may use, download and print the article for any lawful, non-commercial purpose (including text and data mining) provided that all copyright notices and trade marks are retained. 